\title{
Increasing body mass and the mortuary
}

\author{
Roger W. Byard
}

Published online: 13 May 2010

(C) Springer Science+Business Media, LLC 2010

There is mounting evidence that Western nations are in the grip of an obesity 'epidemic'. Average body mass index (BMI) is increasing, with related diseases such as hypertension, atherosclerosis and diabetes mellitus showing concurrent rises [1]. Estimates by the World Health Organization are that the world's population of one billion overweight individuals will increase by another $50 \%$ by 2015 [2]. In the United States alone there has been an increase in morbid obesity in the general population from 0.78 to $2.2 \%$ between 1990 and 2000 [3]. In a forensic context, studies from South Australia have shown an increase in morbidly obese bodies subjected to forensic autopsy from $1.3 \%$ in 1986 to $4.8 \%$ in 2006, with one-third of cases in early 2007 being classified as obese (BMI $\geq 30$ ), and $6 \%$ morbidly obese (Class III, BMI $\geq 40$ ) [4, 5]. All of this significantly affects morgue work practices and even burial techniques are having to be modified, with the need for larger coffins and increased width of cemetery excavations. Thus the situation during life is having a critical impact after death.

This concerning development represents more than just a theoretical issue, as it means that mortuary staff who are often already hard pressed by sheer numbers of cases, are now being confronted with bodies that are often extremely difficult to manoeuver and position. Increasing numbers of obese and morbidly obese victims will result in a number of ongoing problems.

Basic forensic mortuary practice requires the transport of corpses from the place of death or storage to the nearest

\footnotetext{
R. W. Byard ( $\square)$

Discipline of Pathology, The University of Adelaide, Level 3

Medical School North Building, Frome Road, Adelaide,

SA 5005, Australia

e-mail: roger.byard@sa.gov.au
}

forensic facility. In cases of morbidly obese individuals, who may weigh in excess of $300 \mathrm{~kg}$, this may require assistance from emergency services personnel, with special weight lifting hoists and larger transport vehicles. Once such a body has arrived at a mortuary, however, the difficulties may just be starting. In smaller facilities where bodies are routinely manually lifted onto trolleys and then to dissection tables, there is a distinct risk of back injury for staff. An additional problem encountered in obese individuals is a slower rate of cooling than in individuals with BMIs in the normal range. This results in accelerated decomposition making the bodies even more difficult to move, as skin slippage and blistering renders limbs difficult to grip for lifting. Floors can become dangerously slippery with the excessive amounts of decomposed fluid fat that may exude from these bodies. In cases of infections with hepatitis $\mathrm{C}$ or human inmmunodeficiency virus, maintaining safe barrier protection and minimizing exposure will be more difficult given the technical problems of dissecting through many centimeters of subcutaneous adipose tissue with the increased risk of fluid splash. Storage of bodies in standard refrigeration bays may also not be possible due to excessive girth.

Even in morgues where there are hoists and docking systems that use storage trolleys as autopsy tables, there are issues. Standard hoists may not be capable of lifting particularly large bodies, and standard sized tables are not designed to cope with large amounts of excess skin and subcutaneous adipose tissue that may not fit onto table surfaces. Performing adequate external examinations on bodies that are difficult to move or roll, and that may have considerable amounts of body surface concealed within skin folds, may also be taxing for both staff and pathologists.

It is clear that obesity is an increasing problem in all areas of medicine, complicating procedures ranging from 
the finding of subcutaneous veins for simple blood taking, to fitting obese patients into sophisticated imaging machines for magnetic resonance imaging. It should be no surprise, therefore, that autopsy practice has also been adversely affected.

The question arises as to how to best deal with this situation? The optimal solution would be to have purpose built sections of forensic morgues specifically designed to handle individuals with high BMI's. This could be in the form of a special dissection room adjacent to an external wall with a separate door so that bodies could be loaded directly from transport vehicles onto autopsy tables. The room could be refrigerated to remove the need to transport bodies any further before or after autopsy. Hoists designed to lift loads of up to $800 \mathrm{~kg}$ could be installed to enable lifting of bodies to facilitate external inspections. This would not be without cost, however, it would appear that money will have to be spent if autopsy standards are to be maintained in the grossly overweight and if staff health is to be protected. Failure to address these issues in a timely manner may result in difficulties in retaining morgue staff, and in increased claims for work injuries associated with attempts to handle such bodies in suboptimal circumstances. The current trend in increasing body size represents one of the more difficult occupational health and safety issues encountered in forensic facilities in recent years.

\section{References}

1. Hunsaker DM, Hunsaker JC III. Obesity epidemic in the United States: A cause of morbidity and premature death. Ch. 4. In: Tsokos M, editor. Forensic Pathology Reviews, vol. 2. Totowa, NY: Humana Press, Inc; 2004. p. 59-98.

2. Behn A, Ur E. The obesity epidemic and its cardiovascular consequences. Curr Opin Cardiol. 2006;21:353-60.

3. Arterburn DE, Maciejewski ML, Tsefvat J. Impact of morbid obesity on medical expenditure in adults. Int J Obes. 2005;29: 334-9.

4. Byard RW, Bellis M. Significant increases in body mass index (BMI) in an adult forensic autopsy population from 1986 to 2006-implications for modern forensic practice. J Forensic Legal Med. 2008;15:356-8.

5. Byard RW, Bellis M. Increase in adult body weights in coronial autopsies? An impending crisis. Med J Aust. 2007;187:195-6. 